\title{
Verifying Temperature Lapse Rates in the Eastern Himalayas using Landsat 7 and 8
}

\author{
D. J. Penton $^{\text {a }}$, L. E. Neumann ${ }^{\text {b }}$, R. Karki ${ }^{\mathrm{c}}$ and S. Nepal ${ }^{\mathrm{d}}$ \\ ${ }^{a}$ Commonwealth Scientific and Industrial Research Organisation (CSIRO), Land and Water, Australian \\ Capital Territory, Australia, ${ }^{b}$ Commonwealth Scientific and Industrial Research Organisation (CSIRO), \\ Land and Water, Victoria, Australia, ${ }^{c}$ Department of Hydrology and Meteorology, Kathmandu, Nepal, ${ }^{d}$ \\ International Centre for Integrated Mountain Development (ICIMOD), Kathmandu, Nepal \\ Email:dave.penton@csiro.au
}

\begin{abstract}
This paper investigates the use of Landsat-7 and Landsat- 8 thermal bands to assess the accuracy of temperature lapse rate relationships used in hydrological modelling for the Eastern Himalayan region. The temperature at high altitude is an input to conceptual gridded and lumped hydrological models that many studies use to understand and predict the relative contribution of melt-water to streamflow for Himalayan catchments.

Temperature observations in the Eastern Himalayas are limited to meteorological stations below $2000 \mathrm{~m}$ above sea level (ASL), except for a few stations near Mt Everest, that are part of the Ev-K2-CNR project, and some observations from short field campaigns. Many studies extrapolate temperatures at high altitudes from local meteorological observation stations using a temperature lapse rate. The most common method is to develop a seasonal temperature lapse rate from averages of ground-stations, typically between 1000mASL and $2000 \mathrm{mASL}$.

The aim of the analysis was to: a) determine if accurate temperatures at higher altitudes can be calculated from Landsat imagery; b) understand if a linear lapse rate can be inferred from Landsat imagery; and c) investigate the relationship between air temperature and land surface temperature for snow. The method involved (1) identifying cloud-free areas of snow, (2) generating temperature surfaces from Landsat thermal bands using algorithms from Jiménez-Muñoz et al. (2009) and Jiménez-Muñoz et al. (2014), and (3) generating lapse-rate relationships from comparison with elevation surfaces (derived from Aster). The lapse rates generated were cross referenced with ground station measurements and a serendipitous field campaign.

It was found that the correlation between observed temperature at Pyramid station (5035mASL) and Landsat inferred temperature was $0.82 \mathrm{R}^{2}$ (see Figure 1). The correlation degraded as elevation reduced (i.e. to 0.35 $\mathrm{R}^{2}$ at $1732 \mathrm{mASL}$ ). The statistical methods applied were not capable of distinguishing between the contribution of error from the Landsat classification and the error from extrapolation of a linear lapse rate, so it was not possible to determine if the drop in temperature with elevation was linear or non-linear. Further work is required to use this method to confirm that a linear temperature lapse rate is reliable at high elevations. As expected, there were clear differences between temperatures on the northerly and southerly facing sides of mountains. These were especially pronounced during winter.
\end{abstract}

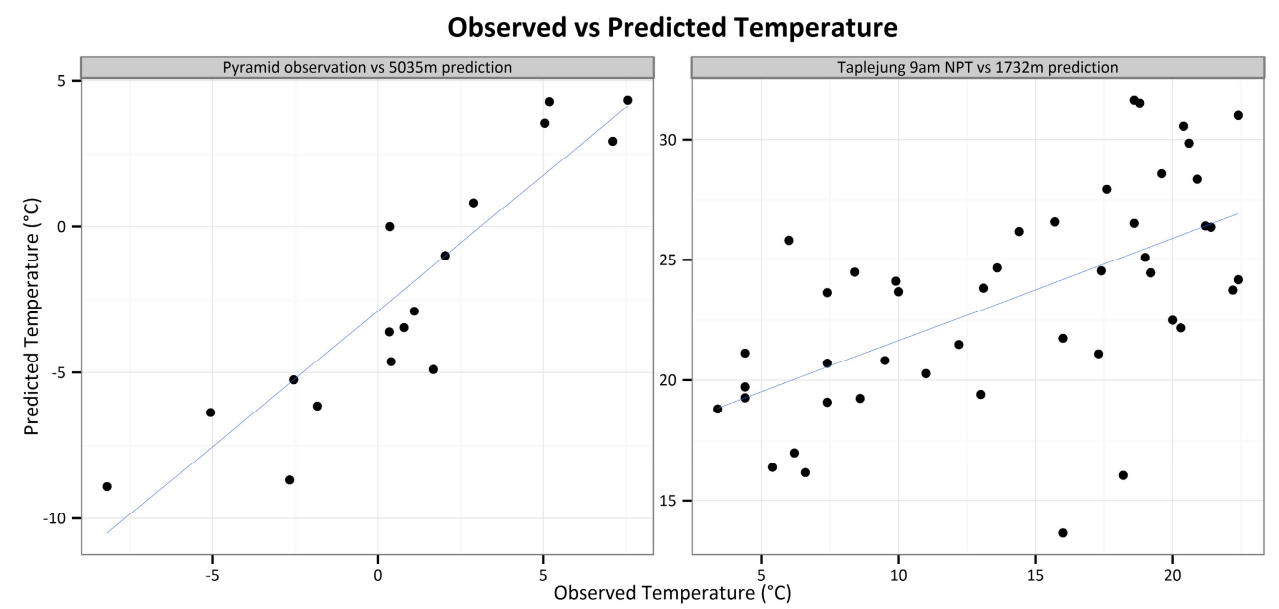

Figure 1. Comparison of observed temperature at meteorological stations to Landsat derived temperature.

Keywords: $\quad$ LandSat 8, Temperature Lapse Rates, Himalayan Catchments 


\section{INTRODUCTION}

The Himalayas have attracted attention from the international community due to the possible effects of a changing climate on the region's environment and the associated livelihoods of the regional population. Scientists have explored many different methods for understanding the region's climate and geography, especially with respect to its glaciers (ice-cores, field measurements, ICE-SAT, GRACE, regional cryosphere models, etc.). In particular, authors such as Lutz et al. (2014) apply distributed hydrology-cryosphere models to understand the impact of climate changes on the regional hydrology. These models require inputs of rainfall and temperature for high altitudes, where temperature is the focus of this paper.

Few in situ measurements of temperature are available at high elevations, limited to Ev-K2-CNR (Tartari et al., 1998) and particular field campaigns. However, the strong winds, low temperatures and inaccessible terrain make it difficult to maintain observation stations above $4000 \mathrm{~m}$. In order to generate inputs, most authors extrapolate from meteorological observations at low/mid elevations $(1500-4000 \mathrm{~m})$ to determine the temperature at high elevations ( $>4000 \mathrm{~m})$, e.g. Pokhrel et al. (2014), Panday et al. (2013), Normand et al. (2010), Nepal et al (2014) and Immerzeel et al. (2014).

This paper focuses on understanding the robustness of extrapolating high altitude temperature from climate stations at lower altitudes. The geographic focus of this study is the Eastern Himalayas (Section 2). The methods involve processing of remotely sensed Landsat imagery to generate temperature surfaces using established techniques (Section 3). The results and conclusions from the analysis are described in (Section 4 and Section 5).

\section{STUDY AREA}

The geographic area of this study is the Tamor catchment in Nepal, which is part of the Eastern Himalayas (as shown in Figure 2). The catchment is a headwater of the Koshi branch which drains into the River Ganges (4005 $\mathrm{km}^{2}$ ). The Tamor catchment was chosen to align with concurrent modelling of the region's hydrology. The catchment varies from sparse forests in the south (representing temperate climate) to snow covered alpine and glacial areas to the north. The catchment is characterised by steep mountainous and alpine environment with monsoonal climate. The mean annual precipitation at Taplejung (\#1405) is $2.2 \mathrm{~m} /$ year with $74 \%$ of the annual rainfall occurring during the summer monsoon between June to September (Nepal, 2012). The mean maximum and minimum temperatures in July at Taplejung are $21^{\circ} \mathrm{C}$ and $13^{\circ} \mathrm{C}$ respectively. The mean maximum and minimum temperatures in January at Taplejung are $12^{\circ} \mathrm{C}$ and $5^{\circ} \mathrm{C}$ respectively.

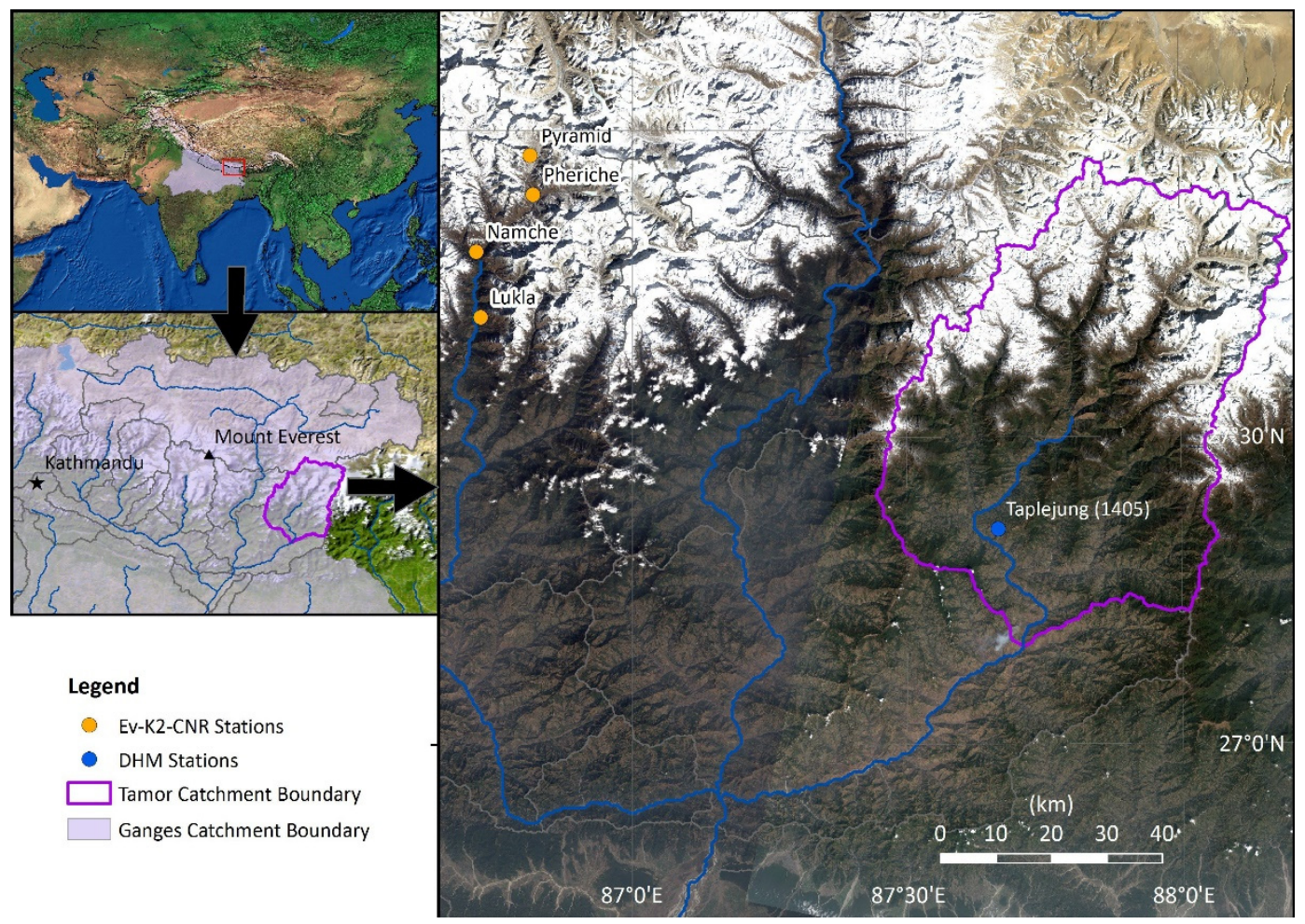

Figure 2. Location of the Tamor catchment and meteorological stations 


\section{METHODS AND MATERIALS}

This section describes the methods applied to relate land surface temperature (from Landsat) to ground observations, and the methods required to generate the required input datasets. Land surface temperature was generated for a series of Landsat 7 and Landsat 8 scenes for the snow covered areas. For each Landsat scene the land surface temperature was related to elevation (e.g. see Figure 3) to examine the lapse rate relation.
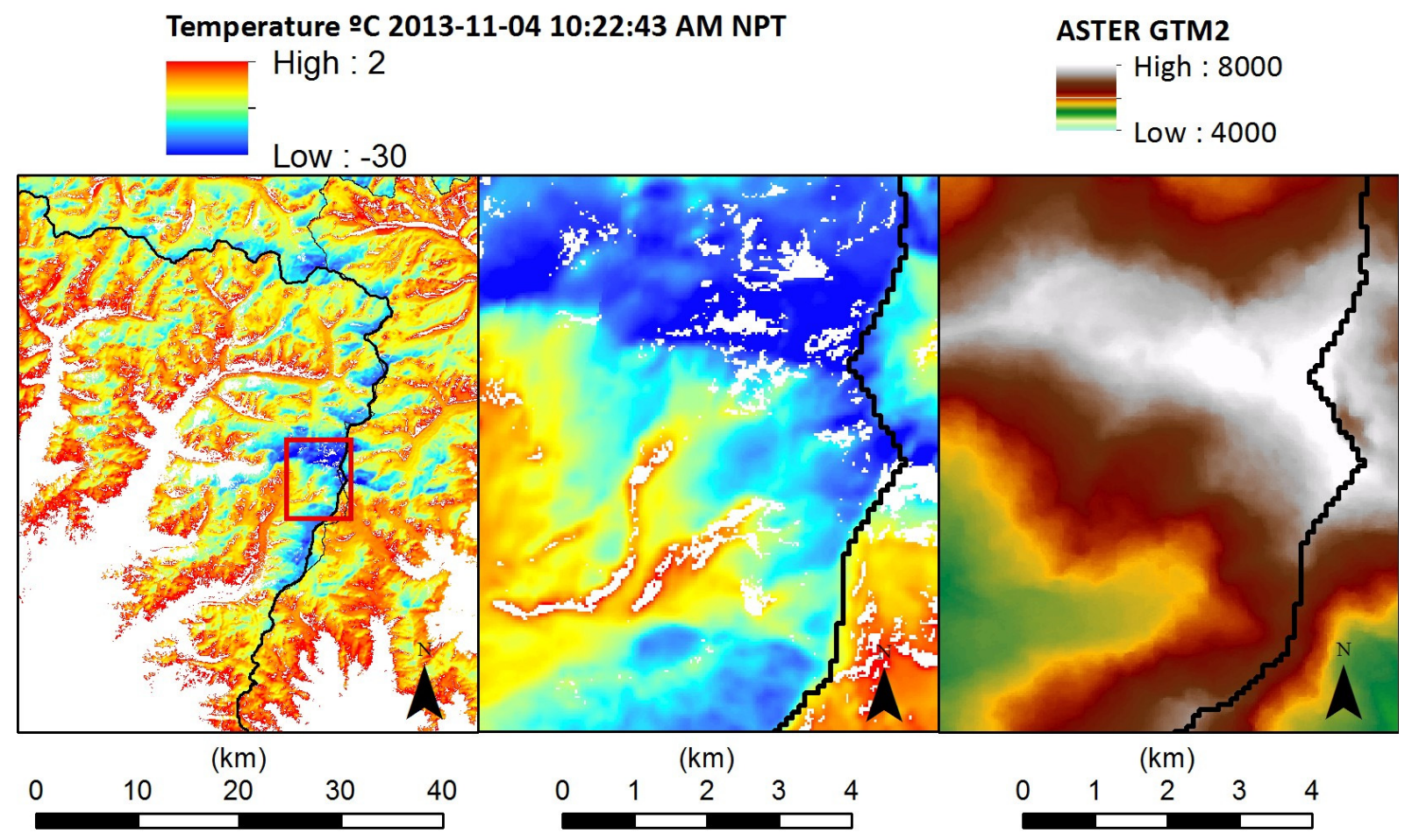

Figure 3. Left: the land surface temperature for 2013-11-04 from Landsat, for the north east region of Tamor. Middle: close up land surface temperature. Right: close up elevation (ASTER DEM (m)) - note the temperature on the northerly aspect is significantly cooler than southerly aspect (e.g. $\left.10^{\circ} \mathrm{C}\right)$.

\subsection{Calculating Surface Temperature}

Based on physical models of blackbody radiation (Planck's Law), the ground temperature can be calculated from the radiance at sensor. Jiménez-Muñoz et al. (2009) define a single channel method for calculating ground temperature using Landsat 5 and 7 data (band 6), and similarly, Jiménez-Muñoz et al. (2014) for calculating ground temperature using Landsat 8 (band 10). The Landsat data was corrected to Level 1T (Standard Terrain Correction). According to Jiménez-Muñoz et al. (2009):

$$
\text { temperature }_{\text {surface }}=\gamma\left[\frac{1}{\varepsilon}\left(\psi_{1} \text { radiance }_{\text {sensor }}+\psi_{2}\right)+\psi_{3}\right]+\delta
$$

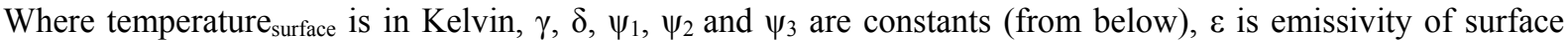

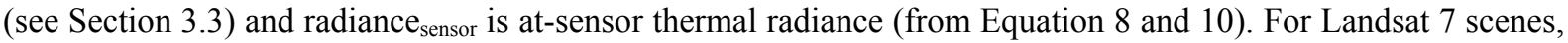
$\psi_{1}$ to $\psi_{3}$ constants derived from the TIG2311 database (see Jiménez-Muñoz et al., 2009) for band 6 are:

$$
\left[\begin{array}{l}
\psi_{1} \\
\psi_{2} \\
\psi_{3}
\end{array}\right]=\left[\begin{array}{ccc}
0.06982 & -0.03366 & 1.04896 \\
-0.51041 & -1.20026 & 0.06297 \\
-0.05457 & 1.52631 & -0.32136
\end{array}\right]\left[\begin{array}{c}
w^{2} \\
w \\
1
\end{array}\right]
$$

Where $\mathrm{w}$ is the atmospheric water vapour content value $\left(\mathrm{gcm}^{-2}\right)$, as calculated in section 3.2. Jiménez-Muñoz et al. (2009) reports a RMSE of 0.7 to $3.1 \mathrm{~K}$ for the TIG2311database values compared to other atmospheric datasets. For Landsat 8 scenes, $\psi_{1}$ to $\psi_{3}$ constants derived from the GAPRI4838 database (see Jiménez-Muñoz et al., 2009) for band 10 are:

$$
\left[\begin{array}{l}
\psi_{1} \\
\psi_{2} \\
\psi_{3}
\end{array}\right]=\left[\begin{array}{ccc}
0.04019 & 0.02916 & 1.01523 \\
-0.38333 & -1.50294 & 0.20324 \\
0.00918 & 1.36072 & -0.27514
\end{array}\right]\left[\begin{array}{c}
w^{2} \\
w \\
1
\end{array}\right]
$$


Where $\mathrm{w}$ is again the atmospheric water vapour content value $\left(\mathrm{gcm}^{-2}\right)$. Jiménez-Muñoz et al. (2014) reports a RMSE of 0.8 to $1.1 \mathrm{~K}$ for variation in the $\mathrm{w}$ of $0.5 \mathrm{gcm}^{-2}$.

According to Jiménez-Muñoz et al. (2009) the $\gamma$ and $\delta$ parameters (parameters related to Planck's function) are:

$$
\begin{gathered}
\gamma \approx \frac{\text { temperature }_{\text {sensor }}{ }^{2}}{b_{\gamma} \text { radiance }_{\text {sensor }}} \\
\delta \approx \text { temperature }_{\text {sensor }}-\frac{\text { temperature }_{\text {sensor }}{ }^{2}}{b_{\gamma}}
\end{gathered}
$$

with $b_{\gamma}$ equals to $1277 \mathrm{~K}$ for Landsat 7 band 6 and $1324 \mathrm{~K}$ for Landsat 8 band 10 , and temperature sensor $_{\text {defined in }}$ Equation 7.

\subsection{Calculating Total Column Water Vapour}

The total column water vapour was extracted from the European Centre for Medium-Range Weather Forecasts (ECMWF) ERA-Interim product. ERA-Interim is a constantly updated global atmospheric reanalysis product (Dee et al., 2011). The atmospheric attribute, "total column water vapour" has a 6 hour temporal resolution and a spatial triangular truncation at 255 (T255 - about $80 \mathrm{~km})$, which was reprojected to a 0.125 degree grid resolution for processing. The total column water vapour with the closest timestamp was used in the modelling.

\subsection{Calculating Emissivity}

Li et al. (2013) reviewed methods for calculating land surface emissivity from satellite data. Many approaches struggle with variance in the surface reflective properties. The better methods require multiple sources of data and/or ground truthing. Snyder et al. (1998) derived reference values for emissivity of snow covered terrain of between 0.977 and 0.995 for MODIS band $31(10.780-11.280 \mu \mathrm{m})$. This study calculated temperature for only the snow covered areas where an average value of 0.988 was used (the resulting temperatures were not sensitive within these tolerances of the MODIS estimate). Note, Landsat 7 band 6 has a spectral range of 10.40-12.50 $\mu \mathrm{m}$ and Landsat 8 band 10 has a spectral range of $10.60-11.19 \mu \mathrm{m}$.

\subsection{Calculating Snow Extents}

This study followed the approach of Dozier (1989). Dozier (1989) investigated the signal in the visible spectrum of snow to bands of the Landsat Thematic Mapper (TM). He determined that snow could be reliably distinguished in the Sierra Nevada (US) according to the formula:

$$
\text { snow }=R_{p}(T M 1)>0.16 \text { and } R_{p}(T M 5)<0.225 \text { and } \frac{R_{p}(T M 2)-R_{p}(T M 5)}{R_{p}(T M 2)+R_{p}(T M 5)}>0.4
$$

where $R_{p}(T M \#)$ is planetary reflectance for each TM band \#, using Equation 9 and 12. Dozier (1989) found that this approach identified snow through minor cloud, but not thick cloud or shadows of mountains. The thresholds can be fine-tuned, visually or based on extra information. The reference values were used in this study.

\subsection{Calculating At Sensor Brightness Temperature}

USGS (2000) and USGS (2015) defines at satellite sensor brightness temperature as:

$$
\text { temperature }_{\text {sensor }}=\frac{K 2}{\ln \left(\frac{K 1}{\text { radiance }}+1\right)}
$$

where temperature sensor $_{\text {was }}$ effective at satellite temperature in Kelvin, radiance was the spectral radiance in $\mathrm{W} / \mathrm{m}^{2} *$ ster $* \mu \mathrm{m}$, and K1 and K2 were constants as defined in the Landsat Handbooks (Table 1 for reference).

Table 1. Landsat calibration constants for ETM+ and TM Thermal Band

\begin{tabular}{|l|l|l|}
\hline & $\mathbf{K 1}\left(\mathbf{W} /\left(\mathbf{m}^{2} *\right.\right.$ ster $\left.\left.* \boldsymbol{\mu m}\right)\right)$ & K2 (Kelvin) \\
\hline Landsat 5 & 607.76 & 1260.56 \\
\hline Landsat 7 & 666.09 & 1282.71 \\
\hline Landsat 8 & K1_CONSTANT_BAND_10 & K2_CONSTANT_BAND_10 \\
\hline
\end{tabular}

\subsection{Calculating Reflectance and Radiance at Sensor (Landsat 7)}

Planetary reflectance $\left(\mathrm{R}_{\mathrm{p}}\right)$ was calculated for Landsat 7 according to USGS (2000) as:

$$
\text { radiance }=(D N-1.0) *\left(\text { radiance }_{\max }-\text { radiance }_{\min }\right) / 254.0+\text { radiance }_{\min }
$$


Penton et al., Verifying Temperature Lapse Rates in the Eastern Himalayas using Landsat 7 and 8

$$
R_{p}=\frac{\pi \cdot \text { radiance. } d^{2}}{E S U N \cdot \cos \theta_{s}}
$$

where $d$ was distance to sun (from daily reference, which varies between 0.98 and 1.01 astronomical units); $\theta_{\mathrm{s}}$ was solar zenith angle in degrees, which was derived from the sun angle defined in the metadata; and ESUN was mean solar exo-atmospheric irradiance, which was $1970 \mathrm{~W} /(\mathrm{m} 2 * \mu \mathrm{m})$ for Band $1,1842 \mathrm{~W} /(\mathrm{m} 2 * \mu \mathrm{m})$ for Band 2 and $225.7 \mathrm{~W} /(\mathrm{m} 2 * \mu \mathrm{m})$ for Band 5 .

\subsection{Calculating Reflectance and Radiance at Sensor (Landsat 8)}

Planetary reflectance $\left(\mathrm{R}_{\mathrm{p}}\right)$ was calculated for Landsat 8 according to USGS (2015) as:

$$
\begin{gathered}
\text { radiance }=\text { DN. } \text { radiance }_{\text {mult }}+\text { radiance }_{\text {add }} \\
R_{p}{ }^{\prime}=\text { reflectance }_{\text {mult }} . D N+\text { reflectance } \\
\text { add }
\end{gathered}
$$

where DN was the digital number in the scene, radiance mult $_{\text {was }}$ the multiplicative rescaling factor from the metadata; and raidiance ${ }_{\text {add }}$ was the additive factor from the metadata. Planetary reflectance $\left(\mathrm{R}_{\mathrm{p}}{ }^{\prime}\right)$ was reflectance without correction for solar angle, with reflectance mult $_{\text {a }}$ multiplicative rescaling factor from the metadata; and reflectance ${ }_{\text {add }}$ was the additive factor from the metadata; and sun $_{\text {elev }}$ was the solar elevation from the metadata.

\section{RESULTS AND CONCLUSIONS}

For each satellite scene, a linear correlation between calculated land surface temperature and elevation (ASTER DEM) was assumed (temperature $=m$. elevation $+c$ ). The relationship was applied to predict temperatures at different elevations for the time of each Landsat scene. The correlation between predicted land surface temperature and observed air temperature was compared for four Ev-K2-CNR stations as well as the Taplejung station (\#1405 at 1732 mASL) from the Nepal government network (see Table 2). The Ev-K2-CNR data were available at near coincident times as the Landsat overpasses. The 9am reading at Taplejung was one to two hours earlier than the Landsat overpass (minimum and maximum values were also compared). For the purposes of the comparison, the difference between air temperature and land surface temperature was assumed to be an unknown constant (calculated as c). Information about the physics of the snow temperature vs air temperature were not considered, but are likely to be important.

The correlation between Landsat derived temperature and elevation - lapse rate - varied for each scene between an $\mathrm{R}^{2}$ of 0.29 and 0.77 , with a mean of 0.48 (see Figure 4). Using a linear fit of temperature vs elevation to predict temperature at lower elevations resulted in poor correlations (e.g. $\mathrm{R}^{2}$ of 0.35 for Taplejung, $1732 \mathrm{mASL}$ ). However, the $\mathrm{R}^{2}$ of the Landsat temperature compared to temperature at the Pyramid high elevation station (5035 mASL) was 0.82 (see Table 2 and Figure 5). For reference, the correlation between observed temperatures at Pyramid and observed temperatures at Taplejung is $0.63 \mathrm{R}^{2}$ (i.e. not using Landsat temperature). The Taplejung station correlated higher with the predicted temperatures at higher elevations (e.g. $5035 \mathrm{mASL}$ ) than the predicted temperature at $1732 \mathrm{mASL}$, which suggests that the line of best fit for each image does not accurately capture the lapse rate for large extrapolations.

Table 2. Correlation between predicted temperatures (linear model) and observed temperatures

\begin{tabular}{|l|l|l|l|}
\hline Dataset & $\mathbf{m}$ & $\mathbf{c}$ & $\mathbf{r}^{\mathbf{2}}$ \\
\hline Pyramid observation vs 5035 m prediction & 0.86 & 2.85 & 0.82 \\
\hline Pheriche observation vs 4260 m prediction & 0.91 & 3.74 & 0.75 \\
\hline Namche observation vs 3570 m prediction & 0.67 & 2.61 & 0.43 \\
\hline Lukla observation vs 2660 m prediction & 0.68 & 1.57 & 0.59 \\
\hline Taplejung max vs 1732 m prediction & 0.55 & 8.92 & 0.35 \\
\hline Taplejung min vs 1732 m prediction & 0.70 & -5.81 & 0.36 \\
\hline Taplejung 9am NPT vs 1732 m prediction & 0.82 & -5.12 & 0.35 \\
\hline
\end{tabular}

The statistical methods applied were not capable of distinguishing between the contribution of error from the Landsat classification and the error from extrapolation of a linear lapse rate, so it was not possible to determine if the drop in temperature with elevation was linear or non-linear. Further work is required to use this method to confirm that a linear temperature lapse rate is reliable at high elevations. There were visual differences between temperatures on the northerly and southerly aspects of mountains (Figure 3). These were especially pronounced 
during winter (not shown). The predicted temperatures were quite accurate, and might provide a useful source of data for especially data sparse regions. Further work is necessary to establish the sensitivity to parameters.
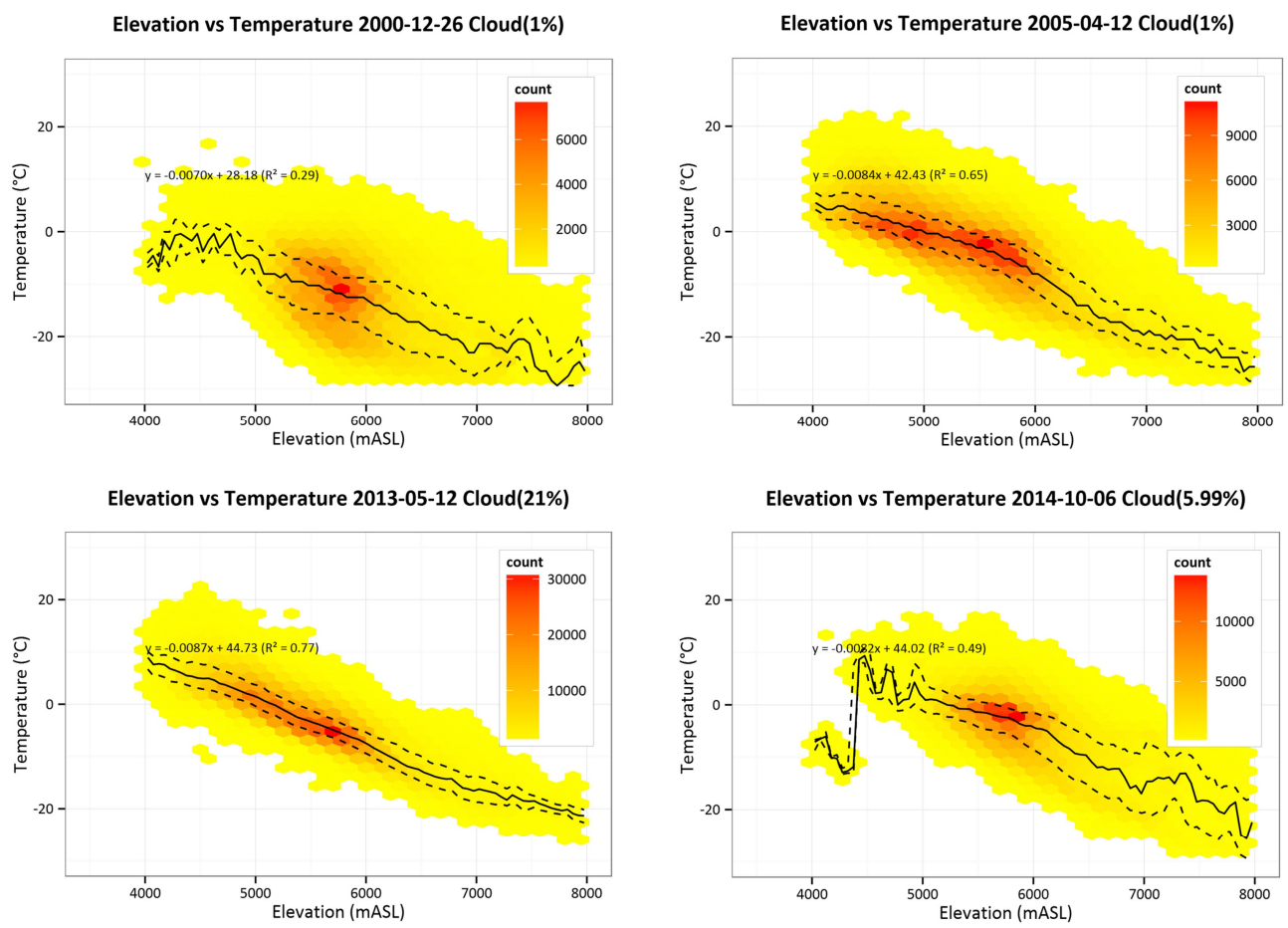

Figure 4. Four graphs of Landsat temperature vs elevation for particular dates (sample of the 45 scenes). The strength of the correlation between temperature and elevation varied between scenes (mean $0.48 \mathrm{R}^{2}$ ). The images above show the density of points at each elevation temperature combination (binned into hexagons according to frequency from yellow to red). The lines represent the $1^{\text {st }}$ quartile (dashed), median and $3^{\text {rd }}$ quartile (dashed) for temperature at each $50 \mathrm{~m}$ elevation interval.

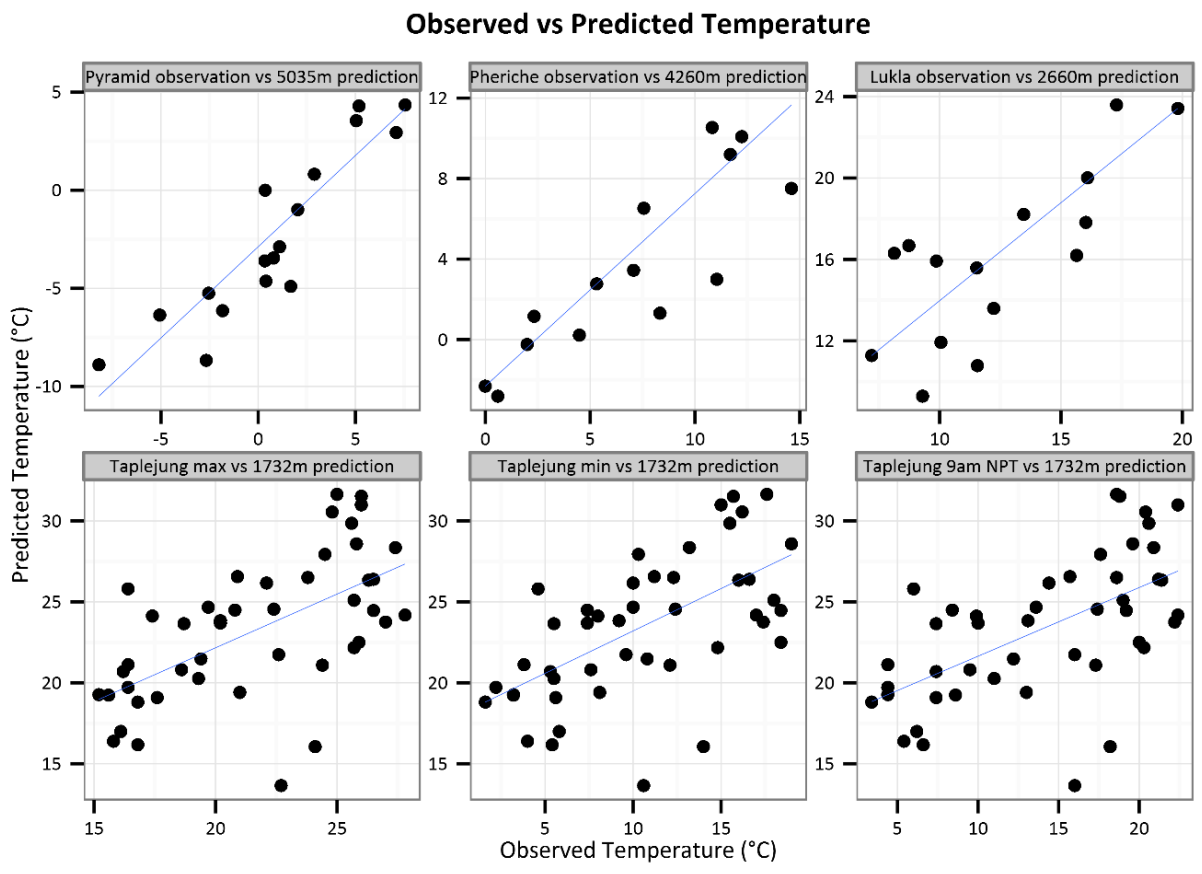

Figure 5. Comparison of observed temperature at three Ev-K2-CNR stations and Taplejung station to predicted temperature from Landsat derived linear temperature gradient. 
Penton et al., Verifying Temperature Lapse Rates in the Eastern Himalayas using Landsat 7 and 8

\section{ACKNOWLEDGMENTS}

The Department of Foreign Affairs and Trade (DFAT) through the South-Asia Development Programme funded this work in CSIRO and ICIMOD. In ICIMOD, this study was undertaken as a part of the Koshi Basin Programme (KBP). This study was partially supported by core funds of ICIMOD contributed by the governments of Afghanistan, Australia, Austria, Bangladesh, Bhutan, China, India, Myanmar, Nepal, Norway, Pakistan, Switzerland, and the United Kingdom.

We acknowledge the assistance of the Department of Hydrology and Meteorology (DHM) and thank the Government of Nepal for allowing us access to hydroclimate data. We acknowledge NASA/Glovis program for providing LANDSAT imagery. We thank the many individuals at DHM, ICIMOD and CSIRO that assisted with data preparation and reviewing of manuscripts. The views and interpretations in this publication are those of the author's and they are not necessarily attributable to their organizations.

\section{REFERENCES}

Dee, D. P., Uppala, S. M., Simmons, A. J., Berrisford, P., Poli, P., Kobayashi, ..., and Vitart, F. (2011), The ERA-Interim reanalysis: configuration and performance of the data assimilation system. Quarterly Journal of Royal Meteorological Society, 137: 553-597. doi: 10.1002/qj.828

Dozier, J. (1989). Spectral signature of alpine snow cover from the Landsat Thematic Mapper. Remote sensing of environment, 28, 9-22.

Immerzeel, W. W., L. Petersen, S. Ragettli, and F. Pellicciotti (2014), The importance of observed gradients of air temperature and precipitation for modeling runoff from a glacierized catchment in the Nepalese Himalayas, Water Resources Research, 50, doi:10.1002/2013WR014506.

Jiménez-Muñoz, J. C., Cristóbal, J., Sobrino, J., Soria, G., Ninyerola, M., \& Pons, X. (2009). Revision of the single-channel algorithm for land surface temperature retrieval from Landsat thermal-infrared data. IEEE Transactions on Geoscience and Remote Sensing, 47(1), 339-349.

Jimenez-Munoz, J. C., Sobrino, J., Skokovic, D., Mattar, C., \& Cristobal, J. (2014). Land surface temperature retrieval methods from Landsat-8 thermal infrared sensor data. IEEE Transactions on Geoscience and Remote Sensing Letters, 11(10), 1840-1843.

Li, Z. L., Wu, H., Wang, N., Qiu, S., Sobrino, J. A., Wan, Z., ... \& Yan, G. (2013). Land surface emissivity retrieval from satellite data. International Journal of Remote Sensing, 34(9-10), 3084-3127.

Lutz, A. F., Immerzeel, W. W., Shrestha, A. B., \& Bierkens, M. F. P. (2014). Consistent increase in High Asia's runoff due to increasing glacier melt and precipitation. Nature Climate Change, 4(7), 587-592.

Nepal, S. (2012). Evaluating Upstream-Downstream Linkages of Hydrological Dynamics in the Himalayan Region. PhD. Thesis. Friedrich Schiller University of Jena, Jena.

Nepal, S., Krause, P., Flügel, W.-A., Fink, M., Fischer, C. (2014). Understanding the hydrological system dynamics of a glaciated alpine catchment in the Himalayan region using the J2000 hydrological model. Hydrological Processes. 28(3), $1329-1344$.

Normand S, Konz M, Merz J. (2010). An application of the HBV model to the Tamor Basin in Eastern Nepal. Journal of Hydrology and Meteorology 7(1): 49-58.

Panday, P. K., Williams, C. A., Frey, K. E., \& Brown, M. E. (2014). Application and evaluation of a snowmelt runoff model in the Tamor River basin, Eastern Himalaya using a Markov Chain Monte Carlo (MCMC) data assimilation approach. Hydrological Processes, 28(21), 5337-5353.

Pokhrel, B. K., Chevallier, P., Andréassian, V., Tahir, A. A., Arnaud, Y., Neppel, L., Bajracharya, O., \& Budhathoki, K. P. (2014). Comparison of two snowmelt modelling approaches in the Dudh Koshi basin (eastern Himalayas, Nepal). Hydrological Sciences Journal, 59(8), 1507-1518.

Snyder, W. C., Wan, Z., Zhang, Y., \& Feng, Y. Z. (1998). Classification-based emissivity for land surface temperature measurement from space. International Journal of Remote Sensing, 19(14), 2753-2774.

Tartari, G., Verza, G. P., \& Bertolani, L. (1998). Meteorological data at the Pyramid Observatory Laboratory (Khumbu Valley, Sagarmatha National Park, Nepal). Limnology of High Altitude Lakes in the Mt. Everest Region (Nepal), 57, $23-40$.

USGS (2000). Landsat 7 science data users handbook. National Aeronautics and Space Administration, Report, 430-15.

USGS (2015). Landsat 8 Data Users Handbook (LSDS-1574 Version 1.0); USGS-Earth Resources Observation and Science: Sioux Falls, SD, USA, 2015. 